\title{
ECOS DE MEMÓRIA DA CULTURA ESCOLAR EM ÁLBUNS FOTOGRÁFICOS: UM PATRIMÔNIO EDUCATIVO
}

\author{
Tânia Regina da Rocha Unglaub ${ }^{1}$ \\ Gisela EggertSteindel $\left.\right|^{2}$
}

\section{INTRODUÇÃO}

Esta texto apresenta resultados parciais de um dos projetos do Programa de Extensão que está sendo desenvolvido, por alunos e professores da Universidade do Estado de Santa Catarina (UDESC) e comunidade da Escola Estadual Básica Jerônimo Coelho na cidade de Laguna (SC). O projeto intitula-se "Ecos de memória da cultura escolar" cujo objetivo é desenvolver atividades relacionadas a guarda e a preservação da memória escolar por meio de vestígios da cultura escolar encontradas em álbuns fotográficos, e quadros de formaturas encontrados nessa instituição educativa. O Programa em desenvolvimento tem o apoio institucional da UDESC por meio da sua Pró-Reitoria de Extensão, Cultura e Comunidade a qual tem como objetivos:

a) promover, incentivar, apoiar e supervisionar programas, projetos, eventos e cursos de extensão; b) promover e supervisionar as atividades acadêmicas no campo social e cultural; c) promover a integração dos segmentos discente, docente e técnico universitário da Universidade; d)promover programas de bolsas acadêmicas no âmbito de suas atividades; e) apoiar e/ou coordenar as promoções comunitárias, culturais, desportivas, sociais e de lazer e da saúde;f) promover e acompanhar intercâmbio com outras instituições no âmbito de sua competência;g)divulgar os seus serviços e atividades de extensão; h) captar recursos através da interação com a comunidade e com os órgãos de fomento e incentivo às atividades de extensão;i) promover e coordenar programas de apoio e assistência voltados à comunidade universitária;j) expeir atos normativos, na esfera de sua competência. (UNIVERDADE DO ESTADO DE SANTA CATARINA, 2016).

\footnotetext{
${ }^{1}$ Professora da Universidade do Estado de Santa Catarina. Centro de Ensino a Distância (CEAD/UDESC). Atua no Mestrado Profissional de Gestão de Unidades de Informação (PPGINFO). Contato: tania.unglaub@udesc.br

${ }^{2}$ Professora da Universidade do Estado de Santa Catarina. Centro de Ciências Humanas e da Educação (FAED). Atua no Programa de Educação e no Mestrado Profissional de Gestão de Unidades de Informação (PPGINFO). Contato: f9giza@gmail.com
} 
O projeto de extensão "Ecos de memória da cultura escolar" faz parte de um programa de extensão, que concorreu ao edital Interno do Programa de Apoio a Extensão da Universidade,(Edital PAEX-UDESC) №. 07/2015 e também conta com a atuação de alunos, professora supervisora e coordenadora de área do Programa Institucional de Bolsa à Docência (PIBID). Esse programa conta com o apoio de recursos federaisdo Ministério da Educação por meio da Fundação CAPES na forma de bolsas do PIBID e tem os seguintes objetivos:

a) Incentivar a formação de docentes em nível superior para a educação básica; b) contribuir para a valorização do magistério; c) elevar a qualidade da formação inicial de professores nos cursos de licenciatura, promovendo a integração entre educação superior e educação básica; d) inserir os licenciandos no cotidiano de escolas da rede pública de educação, proporcionando-lhes oportunidades de criação e participação em experiências metodológicas, tecnológicas e práticas docentes de caráter inovador e interdisciplinar que busquem a superação de problemas identificados no processo de ensino-aprendizagem; e) incentivar escolas públicas de educação básica, mobilizando seus professores como formadores dos futuros docentes e tornando-as protagonistas nos processos de formação inicial para o magistério; e f) contribuir para a articulação entre teoria e prática necessárias à formação dos docentes, elevando a qualidade das ações acadêmicas nos cursos de licenciatura.

Sendo assim, o PIBID viabiliza maior contato de abrangência temporal e reflexiva do graduando com a Escola e interação com a Universidade. O programa de extensão também aproxima a Universidade da comunidade. Nesse sentido a Escola Estadual Básica Jerônimo Coelho na cidade de Laguna (SC) pode contar com apoio desses Programas para trabalhar com a construção de sua memória escolar.

Porém, para além das questões de apoio institucional e recursos financeiros necessários para o desenvolvimento de programas de formação, a presente ação está calcada em um modo de pensar o fazer desta ação de extensão, isto é, o projeto tem um referencial teórico que norteia suas ações, este é o tema do item que segue.

\section{REFERENCIAL TEÓRICO}

Neste item se discutem alguns conceitos inerentes à guarda e a preservação da memória escolar da Escola Estadual Básica Jerônimo Coelho na cidade de Laguna (SC) no entendimento do fazer do Projeto "Ecos de memória da 
cultura escolar". Em outras palavras a abordagem teórica que embala este projeto é a História Cultural que, segundo Chartier (1999), tem por principal objetivo identificar o modo como são constituídos os diferentes lugares e momentos de uma determinada sociedade. A guarda e a preservação de álbuns fotográficos, quadros de formaturas, cadernos e outros possíveis materiais encontrados nessa instituição educativa busca entender como e quando foram produzidos no seu tempo histórico para a tomada de decisão no uso de técnicas de conservação, de preservação ou ainda, quando necessários, técnicas de restauração. Nesse sentido a abordagem da História Cultural é capaz de evocar sensibilidades e compartilhamento de saberes técnicos adequados para o desenvolvimento do tema em questão.

Os objetos encontrados na escola foco desse projeto são verdadeiros relicários que fazem parte de uma cultura escolar que permite a aproximação das práticas do cotidiano por meio de representações da realidade no sentido adotado por Roger Chartier (1990). Para ele, "representação é um produto, resultado de uma prática, historicamente produzida pelas práticas articuladas (políticas, sociais, discursivas) que constroem suas figuras, um sentido" (1990, p. 27).Silvia (2006) comenta que "a compreensão da cultura enquanto práxis, o significado de cultura como conjunto de práticas que conferem determinados significados aos lugares, aos indivíduos e aos grupos, inscreve-se no propósito de construir possibilidades de investigações histórico-educativas". Também menciona que a cultura escolar pode ser compreendida como um conjunto de saberes presentes nas determinações dos mitos, dos comportamentos, das tradições, das inovações e das relações sociais.

Para ViñaoFrago (2006, p. 169) a cultura escolar "expressa ideias, pautas relativamente consolidadas como modo de hábitos. Os aspectos organizados e institucionalizados contribuem para confirmar outros modos de pensar e atuar, que por sua vez, conformam as instituições num outro sentido". Esse autor considera a escola como um lugar de produção de uma cultura, e a relaciona com a história cotidiana do fazer escolar.

As técnicas de conservação, preservação e restauração acima mencionadas são entendidas como estratégias e táticas a partir do pensamento de Michel de Certeau, apresentado por Chartier (2003) em sua obra. Isto é, Michel faz uma distinção entre essas categorias. Para esse autor "As estratégias supõem lugares e instituições, produzem objetos, normas, modelos, acumulam e capitalizam; 
[enquanto que] as táticas, desprovidas de lugar próprio, sem controle sobre o tempo, 'são maneiras de fazer' ou melhor, maneiras de fazer apesar de". Por outro lado, no entanto o conceito de táticas em Certeau (1990), neste projeto, é apreendido no modo próprio a ser criado e aplicado no uso das técnicas de conservação, preservação ou restauração de objetos escolares dessa instituição.

A conservação consiste em métodos técnico-científicos capazes de desacelerar o processo de deterioração instalado em suportes de informação. Já a preservação consiste em [...] inúmeras políticas e opções de ação, incluindo tratamentos de conservação. Preservação é a aquisição, organização e distribuição de recursos a fim de que venham a impedir posterior deterioração ou renovar a possibilidade de utilização de um seleto grupo de materiais [...]. (MILEVSKI, 1997, p. 14).

Assim, para prolongar a vida útil ou impedir a deterioração de suportes impressos é necessário que o acervo siga um programa de preservação e conservação, a fim de manter a integridade física destes. Se isto for realizado, diminuirá a necessidade de se empregar métodos de restauração.

O conceito de restauração implica na aplicação de técnicas e materiais especiais para recuperar ou estancar o processo de perda da obra ou documento. A restauração deve ser realizada atentando para a reversibilidade do processo, isto é, refazer o processo ou técnica aplicada.

Estas técnicas envolvem a higienização do acervo, a conscientização por parte dos usuários, a limpeza do local onde os livros se encontram, o manuseio correto das obras e em especial a prevenção, ou conservação preventiva. O objetivo da conservação preventiva é desenvolver ações de prevenção contra possíveis danos aos livros, além de conscientizar quanto ao correto manuseio e utilização destes. O programa de preservação e conservação destaca a importância de "conservar para não restaurar", poupando o acervo de intervenções custosas e exaustivas.

\section{METODOLOGIA ADOTADA}

A metodologia utilizada para 0 desenvolvimento dessa ação extensionista, que está entrelaçada com as ações do PIBID, seguiu os princípios da 
pesquisa ação preconizada por Thiollant (2011). Para esse autor, este tipo de pesquisa se caracteriza por sondar o contexto, utilizando a observação participante, discutir com os pares a situação problema e intervir diretamente no contexto, com ações que podem inclusive provocar reflexões e até mesmo mudanças nesse espaço, como forma de superar situações problemáticas em questão, denominada como fase intervencionista.

Portanto,educadores, acadêmicos e acadêmicas vinculados ao projeto de extensão e ao PIBID, que atuam na EEB Jerônimo Coelho da cidade de Laguna, SC, por meio da observação participante localizaram dez álbuns fotográficos que revelam práticas pedagógicas e cívicas dos anos de 1930 a 1980 e oito quadros de fotografiasde formatura, sendo que o primeiro quadro é de1918. A comunidade está sendo sensibilizada para a importância desses relicários como patrimônio histórico cultural, como parte da identidade da escola. Como a pesquisa ação prevê um projeto de intervenção com ações a serem realizadas junto à comunidade, foram programadas várias atividades com esta finalidade, para serem desenvolvidas no decorrer do ano letivo.

Trata-se deum trabalho historiográfico de preservação do patrimônio cultural para a construção da memória de uma cultura escolar, com base em fontes documentais da Escola Estadual Básica Jerônimo Coelho. Os documentos são os álbuns fotográficos e quadros de formaturas em couro, datados a partir de 1918 . Esses relicários foram encontrados de forma aleatória na escola. Essas fontes documentais estão sendo higienizadas e digitalizadas paraa guarda e preservação do patrimônio educativo. Esses achados são vestígios de memórias que permitem um diálogo entre o patrimônio educativo e a história da educação, representando uma cultura escolar. De acordo com Dóminique Julia (2001) a culturaescolar,dentrodeumaabordagemhistórica, pode ser considerada comoumamescladenormase práticas"quepermiteatransmissãode conhecimentos eaincorporação decomportamentos" (2001,p.2). Para esse autor a escolatemumahistóriaquenãoé muitodiferenteda históriadeoutrasinstituiçõesdasociedade. A cultura escolar, para ele,evidenciaqueaescolanãoé somenteumlugardetransmissão deconhecimentos, masé, aomesmo tempoetalvezprincipalmente,umlugarde“inculcaçãodecomportamentosedehabitus"(I DEM, p.14).A E.E.B. Jerônimo Coelho pertence à Rede Pública Estadual de Ensino 
e foi fundada em 1912, sendo a segunda escola construída no estado e representa um patrimônio histórico e cultural para a historiografia da educação catarinense. Note-se que a foto mais antiga já encontrada nessa pesquisa remonta os primórdios da instituição, considerando sua data de fundação e a foto de uma formatura 6 anos depois.

Além da higienização e digitalização dos referidos documentos, foram organizadas algumas atividades sociais e comunitárias para aproximar a comunidade da escola e universidade. Como parte dessas atividades, consta a participação de ex-alunos para que disponibilizem materiais de seu tempo estudantil, bem como visualizemo acervo que está sendo organizado e colocado numa sala de memória. Para isso foi promovido um encontro com ex-alunos na escola onde houve momentos de confraternização

Como a pesquisa ação prevê momentos de estudos e discussões com o grupo envolvido, também estão sendo oportunizados momentos de estudos com leituras de artigos científicos sobre preservação e conservação do acervo. Os seminários de discussões e estudos envolvem acadêmicos do curso de pedagogia a distância que são participantes do PIBID e programa de extensão, professores da escola envolvida e professores da universidade. Todos atentos com olhar voltado a preservação da história da instituição para compreender a cultura escolar vivenciada nesta escola durante mais de um século.

\section{RESULTADOS INICIAIS}

Como apontado no início deste texto o trabalho de extensão em questão tem sidodesenvolvido junto à comunidade do entorno da escola por alunos do curso de pedagogia a distância do CEAD/UDESC que fazem parte do Programa Institucional de Bolsa de Iniciação à Docência (PIBID), financiado com verba do Ministério da Educação via CAPES. O objeto de estudosão fontes documentais, pois trata-se de álbuns fotográficos de práticas escolares e quadros emoldurados de formandos e educadores pioneiros da escola. Os envolvidos no projeto realizaramuma sondagem prévia e observaram o desejo da comunidade escolar em conhecer e preservar o patrimônio escolar por meio da construção e aproximação da cultura escolar contida nesses documentos de muitas 
décadas atrás. Estes objetos foram localizados no ano 2015 pela professora supervisora do PIBID que exerce a docência no CEAD/UDESC.

Como resultado parcial observa-se 0 entrelaçamento entre pesquisa, ensino e extensão, e entre professores e acadêmicos que participam do projeto. Os participantes organizaram grupos de estudos para a compreensão do conceito de cultura escolar, patrimônio educativo, orientações sobre preservação e arquivamento. Tais estudos proporcionaram a compreensão de queos quadros fotográficos, álbuns, cadernos antigos e cadeiras encontrados casualmente num canto da escola, são patrimônios históricos que contam a história daquela instituição educativa. Os documentos estão sem ser manuseados há muitas décadas, uma das primeiras tarefas foi a higienização e digitalização do material.

Além dos resultados mencionados, que se evidenciarampela interação dos participantes e apropriação da história da instituição educativa, se destaca a organização da sala de memória, onde estão sendo guardados os materiais já higienizados e catalogados. A interação entre a Universidade, escola e comunidade nesse projeto de extensão se efetuou pelapresença e participação da comunidade escolar e do entornono projeto bem como o interesse na visitação à sala de memória. Dessa forma o entrelaçamento entre ensino, pesquisa e extensão, consegue a sensibilização historiográfica da cultura escolar. Houve encontros entre ex-alunos, alunos, educadores da escola e professores da universidade.

Importa relatar que os álbuns fotográficos da década de 30, 40 e 50 já foram utilizados para estudos de história no quarto e quinto anos do ensino fundamental da referida escola. Os alunos analisaram o uniforme da época e despertaram a curiosidade em conhecer a história que envolveu aquela indumentária. O projeto está em andamento, mas os resultados já estão ultrapassando os objetivos inicias do projeto "Ecos de Memória da Cultura Escolar".

\section{CONCLUSÕES PROVISÓRIAS}

Este trabalho relata os processos já desenvolvidos sobre a guarda e a preservação desses achados. Esses vestígios possibilitam a compreensão da trajetória histórica da Escola Estadual Jerônimo Coelho, bem como representam suas práticas e saberes vivenciados em seu interior. Acadêmicos da graduação, 
professores da universidade, docentes e seus alunos daquela unidade escolar e comunidade do entorno da escola estão tendo a oportunidade de aproximar-se da cultura escolar e da história da educação através da preservação do patrimônio educativo daquela instituição.

Esse programa de extensão têm sido desenvolvido na perspectiva da indissociabilidade entre ensino, pesquisa e extensão e já apresenta importantes análises e reflexões no campo da historiografia educativa.

\section{REFERÊNCIAS}

BRASIL. Ministério da Educação. Fundação CAPES. (Pibid) Programa Institucional de Bolsa à Docência. Brasília, 2016. Disponível em: http://www.capes.gov.br/educacao-basica/capespibid. Acesso em 10 de junho de 2016.

CERTEAU, Michel. A invenção do cotidiano. Rio de Janeiro: Vozes, 1990.2v.

CHARTIER, Roger. A História Cultural: entre práticas e representações. Rio de Janeiro: Bertrand do Brasil, 1990.

CHARTIER, Roger. Formas e sentido cultura escrita: entre distinção e apropriação. Campinas, SP: Mercado Aberto; Associação de Leitura do Brasil, 2003.

JULIA,Dóminique.Aculturaescolarcomoobjetohistoriográfico.Tradução:Gizelede

Souza. Revista BrasileiradeHistóriadaEducação, SãoPaulo,n.1,p.9-44, 2001.

MILEVSKI, R. J. Manual de pequenos reparos em livros. Rio de Janeiro: Projeto Conservação Preventiva em Bibliotecas e Arquivos: Arquivo Nacional, 1997.

SILVA, Fabiane de Cássia Tavares. Cultura Escolar: Quadro conceitual e possibilidades de pesquisa. Revista Educar, Curitiba (PR) v. 28,p. 201 -216, 2006.

VIÑAOFRAGO,Antonio.Sistemas educativos, Culturas escolares y reformas. 2. ed. Madri: Morato, 2006. 
UNIVERSIDADE DO ESTADO DE SANTA CATARINA. Pró-Reitoria de Extensão, Cultura e Comunidade. Atribuições [...]. Florianópolis, 2016. Disponível em http://www.udesc.br/?id=62. Acessado em 10 de junho 2016.

Fonte de financiamento:O programa de extensão concorreu ao Edital PAEXUDESC $07 / 2015$ e foi contemplado com financiamento para o a execução do programa ficando em segundo lugar no rank da UDESC. 